\title{
German Cockroach Antigen IgA Antibody Measurement
}

National Cancer Institute

\section{Source}

National Cancer Institute. German Cockroach Antigen IgA Antibody Measurement. NCI

Thesaurus. Code C130141.

A measurement of the German cockroach (Blattella germanica) antigen IgA antibody in a biological specimen. 